Respiration 2015;89:88

DOI: $10.1159 / 000367898$

\section{Autobullectomy in Patients with COPD}

Wouter H. van Geffen, Dirk-Jan Slebos

Department of Pulmonary Diseases, University Medical Center Groningen, University of Groningen, Groningen, The Netherlands

In patients with severe emphysema, surgical or novel bronchoscopic lung volume reduction therapies are potential additional treatment options that can result in significant improvements in pulmonary function, exercise capacity and quality of life [1-4]. At our Department of Pulmonary Diseases, we receive hundreds of referrals for these interventions every year. We have been able to observe Nature at work in several of these patients; 3 of our patients have reported a significant spontaneous improvement in exercise performance and quality of life over the past years without having to have any medical intervention. After a careful review of their medical charts, pulmonary function tests and available radiological imaging, it appeared that all 3 showed a significant improvement in pulmonary function, which occurred after visible changes on their chest X-ray or chest CT scans. These reported measurements were all taken with the patients in a stable state.

In all 3 patients, chest imaging showed a significant volume reduction of the previously most diseased parts of their lungs (fig. 1). In the first patient, a 44-year-old male, this was preceded by a large, infected bulla occupying about half of the right thoracic volume, and concurrent pneumonia. Before the event, he had had an $\mathrm{FEV}_{1}$ of 0.81 liters ( $20 \%$ of predicted) and a residual volume (RV) of 7.49 liters (378\% of predicted), both of which improved [to FEV 1.75 liters (44\% of predicted) and RV 4.85 liters (233\% of predicted)].
In the other 2 patients, no specific clinical event preceding the spontaneous improvement was reported. In the second patient, a 56-year-old male, $\mathrm{FEV}_{1}$ was 0.72 liters ( $18 \%$ of predicted) and $\mathrm{RV}$ 7.71 liters (320\%), improving to 1.17 liters (30\% of predicted) and 5.48 liters (227\% of predicted), respectively. In the third patient, a 65 -year-old male, $\mathrm{FEV}_{1}$ was 0.84 liters (24\% of predicted) and RV was 6.39 liters (261\% of predicted), changing to 1.03 liters (29\%) and 4.79 liters (190\% of predicted), respectively.

Although almost every pulmonary physician might be able to memorize a similar remarkable case of 'natural improvement' from their own practice, surprisingly, after a thorough search of the literature, there are only a few reports of patients having had a spontaneous lung volume reduction or so-called 'autobullectomy' [5]. This natural course is an exciting finding, and its significant benefit for our patients also demonstrates the potential impact of lung volume reduction therapies in this patient group. Recognizing autobullectomy furthermore helps the understanding of sudden changes in the natural course of COPD.

\section{References}

1 Fishman A, Martinez F, Naunheim K, et al: A randomized trial comparing lung-volume-reduction surgery with medical therapy for severe emphysema. N Engl J Med 2003;348:2059-2073.

- 2 Herth FJ, Eberhardt R, Gompelmann D, et al: Radiological and clinical outcomes of using Chartis ${ }^{\mathrm{TM}}$ to plan endobronchial valve treatment. Eur Respir J 2013;41:302-308.

-3 Slebos DJ, Klooster K, Ernst A, et al: Bronchoscopic lung volume reduction coil treatment of patients with severe heterogeneous emphysema. Chest 2012;142:574-582.

4 Gasparini S, Zuccatosta L, Bonifazi M, et al: Bronchoscopic treatment of emphysema: state of the art. Respiration 2012;84:250-263.

5 Goodman RB, Lakshminarayan S: Images in clinical medicine. Inflammatory autobullectomy. N Engl J Med 1996;23:1372-1373.
Fig. 1. Chest X-rays of patient number 1 (a 44-year-old male). a Bilateral severe emphysema. b Autobullectomy of the right upper lobe, which resulted in a remarkable spontaneous clinical improvement.
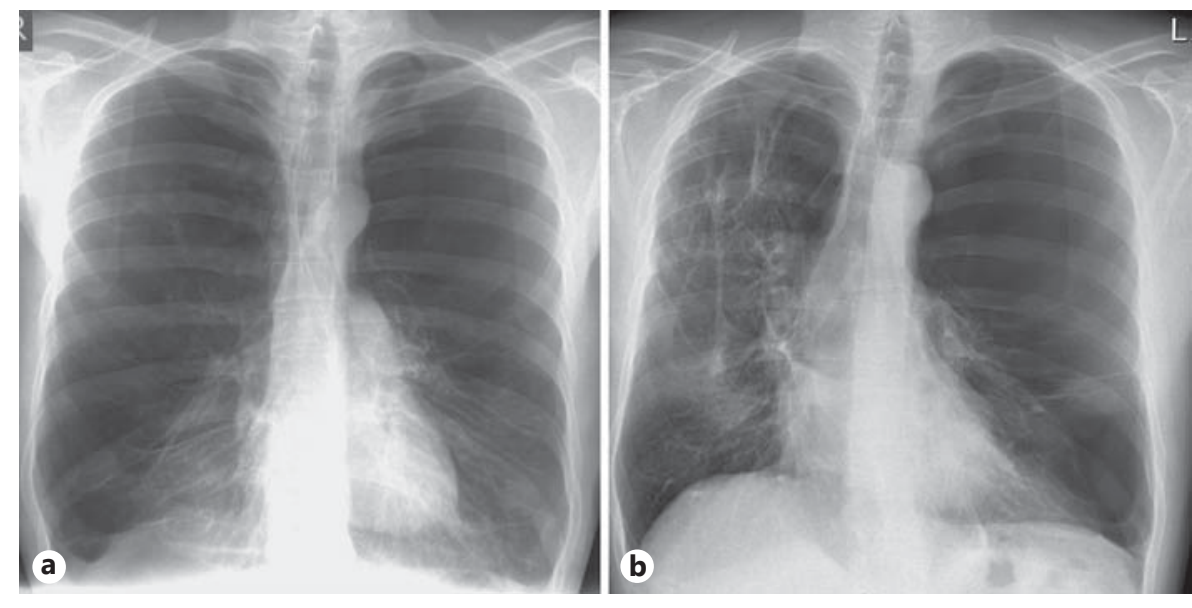

\section{KARGER 125}

(c) 2014 S. Karger AG, Base

0025-7931/14/0891-0088\$39.50/0
Dirk-Jan Slebos, MD, $\mathrm{PhD}$

Department of Pulmonary Diseases, AA11

University Medical Center Groningen, PO Box 30001

NL-9700 RB Groningen (The Netherlands)

E-Mail d.j.slebos@ umcg.nl 